\title{
The male genitalia of ants: musculature, homology, and functional morphology (Hymenoptera, Aculeata, Formicidae)
}

\author{
Brendon E. Boudinot ${ }^{\prime}$ \\ I The Evergreen State College, 2700 Evergreen Parkway NW, Olympia, WA 98505, USA \\ Corresponding author: Brendon E. Boudinot (boudinotb@gmail.com)
}

Academic editor: Jack Neff | Received 17 July 2012 | Accepted 12 December 2012 | Published 30 January 2013

Citation: Boudinot BE (2013) The male genitalia of ants: musculature, homology, and functional morphology (Hymenoptera, Aculeata, Formicidae). Journal of Hymenoptera Research 30: 29-49. doi: 10.3897/JHR.30.3535

\begin{abstract}
The genitalia of male ants are interpreted in the context of the broader Hymenoptera. For the first time muscle homologies are established for twenty six species of ants in nine subfamilies: Amblyoponinae, Cerapachyinae, Dolichoderinae, Ecitoninae, Ectatomminae, Formicinae, Leptanilloidinae, Myrmicinae and Ponerinae. Fifteen muscles in total are found in the external genitalia of male ants and all are homologous with the musculature of basal Hymenoptera (Schulmeister 2001). Secondary fusion, reduction or losses of muscles have occurred in different lineages. From generalized to derived, the functional morphology and qualitative mechanics of three taxa, Formica obscuripes Forel 1886, Messor andrei Mayr (1886) and Labidus coecus Latreille (1802) are described and compared. Special reference is made to the Ecitoninae, where the work of Birket-Smith (1981) is reinterpreted and volsellar homology is clarified. The true digitus of Labidus is revealed to be a small sclerite at the base of the distal volsellar element which is re-identified as the cuspis.
\end{abstract}

\section{Keywords}

Anatomy, army ants, kinesiology, morphology, reproductive biology

\section{Introduction}

Insect male genitalia are spectacular mechanical adaptations with diverse morphology and function. Examples of this diversity include the twin hypodermic intromittent organs of the Drosophila bipectinata complex (Kamimura 2007), the sperm scoopulas of Odonata (Córdoba-Aguilar et al. 2003), 'Symphytan' suction cups (Schulmeister 2001), the copu-

Copyright Boudinot BE. This is an open access article distributed under the terms of the Creative Commons Attribution License 3.0 (CC-BY), which permits unrestricted use, distribution, and reproduction in any medium, provided the original author and source are credited. 
latory hooks of Metrioidea (Chrysomeloidea; Flowers and Eberhard 2006), and genitalia modified as stridulatory instruments for courtship (Micronecta, Corixidae; Sueur et al. 2011) or for stridulation in copulo (Tipula, Tipulidae; Eberhard and Gelhaus 2009). The diversity of male genitalia may also be cryptic and in the realm of functional morphology. For example, male Drosophila melanogaster with ablated genital clasper mechanosensory sensillae were found to copulate less frequently, and unilaterally ablated males mounted females skewed contralaterally from the typical position (Acebes et al. 2003).

The morphology and mechanics of male ant genitalic musculature remain undescribed for all $-12,000$ species of ants (Bolton 1995), with the exception of Labidus coecus, Dorylus (Anomma) funereus (Birket-Smith 1981), and Myrmica kotokui Forel 1911 (Ogata 1991). The function of ant genitalic valves has been described from primary observations for few taxa (Allard et al. 2002, 2006; Baer and Boomsma 2006), while the entire sequence of copulation has never been reported; a composite description is as follows. Copulation of all non-'Symphyta' Hymenoptera is orthandrous (i.e. male atop female, facing same direction; Schulmeister 2001), which holds true for ants. Males of Carebara vidua F. Smith 1858 and Plectroctena mandibularis F. Smith 1858 were observed to use their genitalia to probe the apex of the female's gaster while grasping her with his legs (Robertson and Villet 1989; Villet 1999). Probing is likely a general requisite of ant copulatory behavior (Ross 1982; Schulmeister 2001) followed by penetration which may be via the penisvalvae apices, the digiti or both. The penisvalvae of the aedeagus anchor the male inside of the female's bursa copulatrix or the mussel organ of Atta (Baer and Boomsma 2006), sometimes causing female scarring (Kamimura 2008) while the endophallus is putatively everted (Allard et al. 2002; although see Schulmeister 2001). The typically opposable digitus and cuspis have been observed to clasp the terminal female sternite in a ponerine Diacamma sp. (Allard et al. 2002). The parameres serve as a clamp-type attachment mechanism (Gorb 2008; Ogata 1991; Schulmeister 2001), potentially enhanced by wet adhesion from a putative telomeral gland (Francoeur 1988). The male will often release grasp the female and hang on to her by his genitals only (Robertson and Villet 1989) and will remain anchored within the female in this position during a variable period of time until copulation is terminated (Hölldobler and Wilson 1990; Foitzik et al. 2002).

Knowledge of genitalic functional morphology contributes to our understanding of the sexual selection pressures which act on these organs (Eberhard 2010) and may possibly be used to make predictions about the reproductive biology of ants. This is of significance given the effects of mating systems (Boomsma et al. 2005), paternity assurance (Baer 2011; Baer and Boomsma 2006) and polyandry (Hughes and Boomsma 2007; Robinson and Page Jr. 1989) on social dynamics. Furthermore, understanding male ant morphology is important for taxonomy (Fisher 2009; LaPolla et al. 2012; Yoshimura and Fisher 2012) and systematics (LaPolla 2004; Brady and Ward 2005). Thus the musculature and gross morphology of male ant genitalia represents an appealing and untapped source for new, potentially useful morphological characters (Keller 2011; Schulmeister 2003; Song and Bucheli 2010), which may also serve as synapomorphies for clades identified via molecular techniques. 
The goal of this paper is to discuss the homologies of male ant genitalic musculature in the context of the broader Hymenoptera and to provide descriptions of the functional mechanics of three distinct forms. The work of Schulmeister $(2001,2003)$ has identified and clarified the muscular homologies within the basal Hymenoptera, or the paraphyletic 'Symphyta' (Sharkey 2007). While the external genitalia of male ants have been characterized for several subfamilies (Ogata 1991; Yoshimura and Fisher 2009, 2011, 2012; Yoshimura and Onoyama 2002), musculature has been completely overlooked excepting Birket-Smith (1981) and Ogata (1991), the former of which is here reassessed.

\section{Materials and methods}

All specimens examined in this study were from the author's personal collection (BEBC) or the Longino collection (JTLC, University of Utah). Collections in 95\% ethanol were made in Central America, and in the states of Arizona, California, Tennessee and Washington. Specimens were softened by boiling in water for 2-5 minutes. Dissections were carried out in petri dishes, with or without wax and minuten pins. A Leica MZ16 microscope with maximum magnification of $115 \times$ and mounted with a JVC Digital Camera KY-F708 3-CCD was used for dissections. Micrographs were generated for illustration using Auto-Montage Pro Syncroscopy (Synoptics Ltd., Frederick, MD USA) software. For especially small males, temporary mounts of minute sclerites and musculature were prepared for observation with a Leica DME compound microscope using glycerin as the mounting medium.

General hymenopteran terms preferred by the Hymenoptera Anatomy Ontology (Yoder et al. 2010) are used when homology is clear (Table 1). For an overview of terms applied to the genitalia of ants and other Hymenoptera, refer to Yoshimura and Fisher (2011) and Schulmeister (2001). Walker Jr. and Liem's (1994) concepts of origin and insertion are used when discussing musculature: origins are broad anchoring attachments; while insertions are the narrow, usually distal or posterior, ends of muscles which transfer force to a movable element. The muscles of hymenopteran male genitalia are named alphabetically (Boulangé 1924; modified by Schulmeister 2001): anterior to posterior, ventral to dorsal, medial to lateral; starting with sternum IX and ending with the muscles of the parameres. Thus lettering begins on the anteroventral apex of sternum IX with muscle $a$ and ends, in the Formicidae, with the intrinsic muscle $t$ of the parameres.

The mechanics of sclerite movement were assessed qualitatively by examining the angles of muscular origin and insertion, and the attachment or position of the sclerite relative to the local components of the genital capsule. Simple physical models were used to predict the mechanics of muscular contraction and element movement. Formica obscuripes Forel 1886, Messor andrei Mayr (1886) and Labidus coecus Latreille (1802) were chosen as models for functional morphology because their genitalia are well developed, represent cases of relatively generalized to specialized morphology, and 
Table 1. Anatomical terms of the external genitalia used herein, excluding specific membrane and apodeme names. Hymenoptera Anatomy Ontology (HAO) Uniform Resource Identifiers (URIs) link to concept definitions. Synonyms discussed or used are indicated.

\begin{tabular}{l|l|c}
\hline \multicolumn{1}{c|}{ Term } & \multicolumn{1}{c}{ HAO URI } & Synonyms \\
\hline Aedeagus & http://purl.obolibrary.org/obo/HAO_0000091 & \\
\hline Apex gonostipitis & http://purl.obolibrary.org/obo/HAO_0000134 & \\
\hline Apodeme & http://purl.obolibrary.org/obo/HAO_0000142 & \\
\hline Apophysis & http://purl.obolibrary.org/obo/HAO_0000143 & \\
\hline Cupula & http://purl.obolibrary.org/obo/HAO_0000238 & Basal ring \\
\hline Basivolsella & http://purl.obolibrary.org/obo/HAO_0001085 & \\
\hline Digitus & http://purl.obolibrary.org/obo/HAO_0000385 & \\
\hline Cuspis & http://purl.obolibrary.org/obo/HAO_0000239 & Distivolsella \\
\hline Endophallus & http://purl.obolibrary.org/obo/HAO_0000291 & \\
\hline Foramen genitale & http://purl.obolibrary.org/obo/HAO_0000346 & \\
\hline Genital capsule & http://purl.obolibrary.org/obo/HAO_0000312 & \\
\hline Gonocondyle & http://purl.obolibrary.org/obo/HAO_0000380 & \\
\hline Gonopore & http://purl.obolibrary.org/obo/HAO_0000821 & \\
\hline Basimere & http://purl.obolibrary.org/obo/HAO_0000386 & Gonostipes \\
\hline Gonostipital arm & http://purl.obolibrary.org/obo/HAO_0000387 & \\
\hline Telomere & http://purl.obolibrary.org/obo/HAO_0000395 & Harpe \\
\hline Paramere & http://purl.obolibrary.org/obo/HAO_0000389 & \\
\hline Parossiculus & http://purl.obolibrary.org/obo/HAO_0000703 & \\
\hline Penisvalva & http://purl.obolibrary.org/obo/HAO_0000707 & \\
\hline Phallotrema & http://purl.obolibrary.org/obo/HAO_0000714 & \\
\hline Spiculum & http://purl.obolibrary.org/obo/HAO_0000946 & \\
\hline Valviceps & http://purl.obolibrary.org/obo/HAO_0001047 & \\
\hline Valvura & http://purl.obolibrary.org/obo/HAO_0001050 & \\
\hline Volsella & http://purl.obolibrary.org/obo/HAO_0001084 & \\
\hline & & \\
\hline
\end{tabular}

among these three taxa all the observed genitalic muscles of male ants are represented. The more complicated movements described here should be treated as predictions to be tested either via direct observation of copulation or via neuroethological studies.

\section{Results and discussion}

\section{Genitalic morphology (Figs 1-17)}

\section{External genitalia (Figs 1-16)}

The external genitalia of ants are composed of five elements: sternum IX, the cupula, and the paired valves of the penisvalvae, volsellae, and parameres (Figs 1-4). Sternum IX (Fig. 4) is produced anteromedially into a process called the spiculum (Schulmeister 2001) and has a cranial apodeme traversing the mesal face (Forbes 1967; Forbes and 


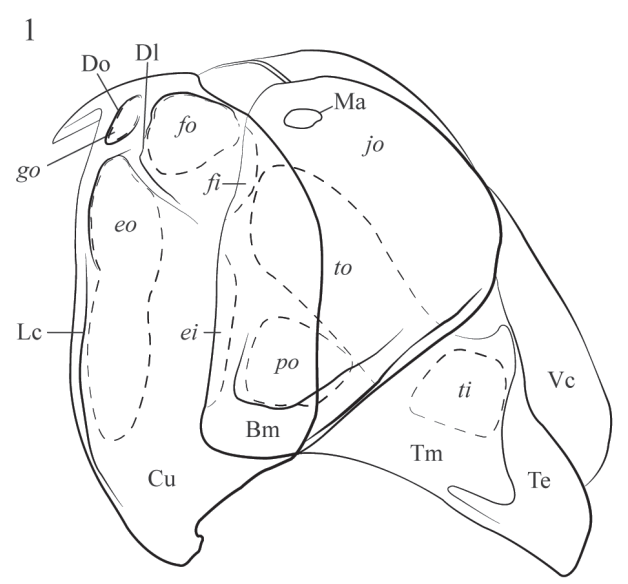

2
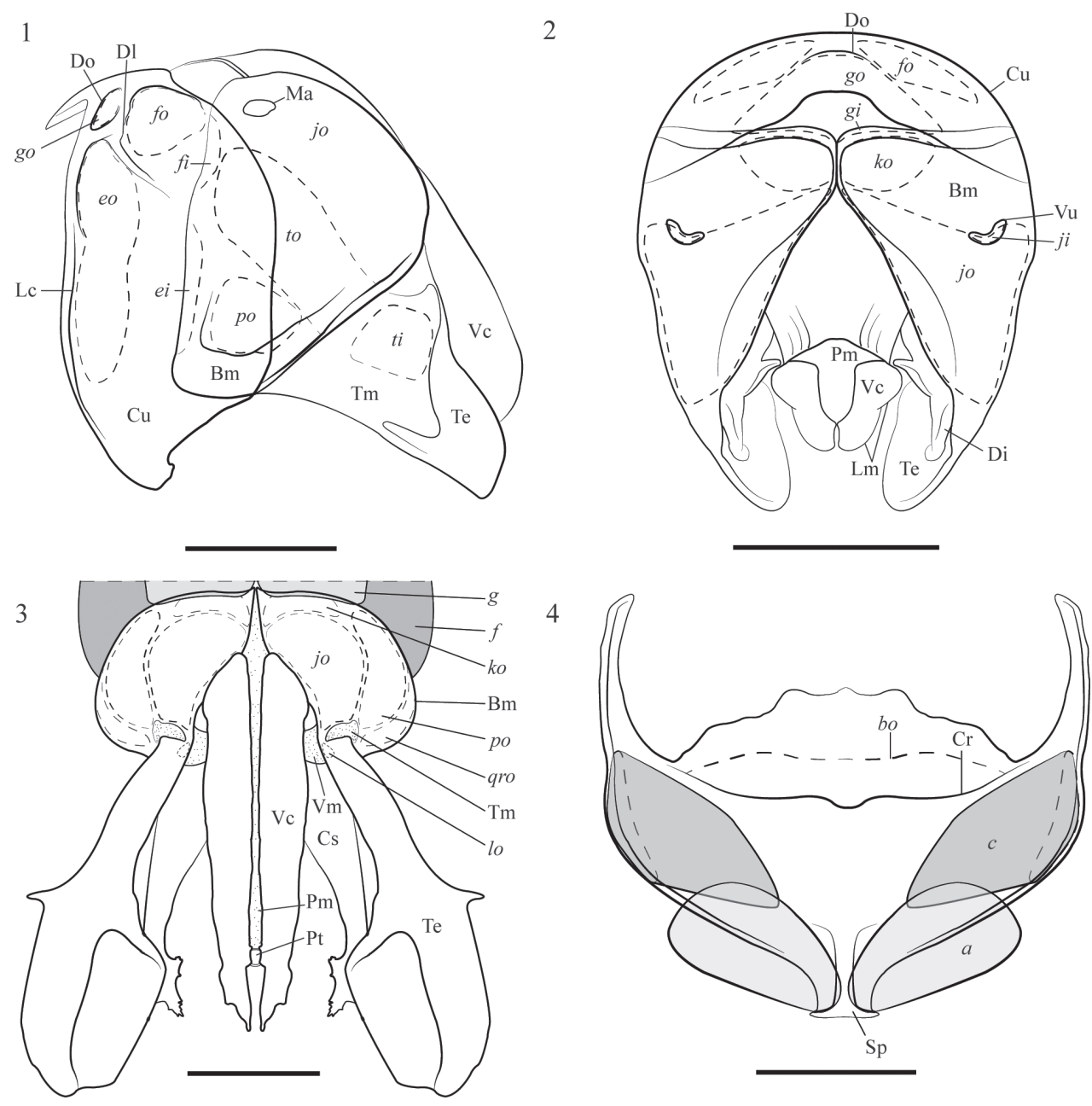

Figures I-4. Genital capsule and sternum IX habitus and musculature. I Formica obscuripes lateral oblique view, $0.5 \mathrm{~mm} 2$ Messor andrei dorsal view, $0.5 \mathrm{~mm} 3$ Labidus praedator dorsal view, $1.0 \mathrm{~mm}$ 4 F. obscuripes sternum IX anterior-to-posterior oblique mesal view, $0.5 \mathrm{~mm}$. Abbreviations: $\mathbf{B m}$ basimere; Cr cranial apodeme of sternum IX; Cs cuspis; Cu cupula; Di digitus; Dl dorsolateral apodeme of cupula; Do dorsal apodeme of cupula; Lc lateral apodeme of cupula; Lm valviceps lamina; Ma maculation; Pm penisvalva membrane; $\mathbf{P t}$ phallotrema; Sp spiculum; Te telomere; Tm telomeral membrane; Vm volsellar membrane; Vu valvura. Muscles: $a b c$ d e f g h $i j k l p q r t$ insertion of muscle ' $x$ ': $x i$; origin of muscle ' $x$ ': $x o$.

Hagopian 1965), which may be a modified sternal antecosta. The term cupula is preferred over basal ring, as the latter refers to non-homologous structures in the Protura and Diptera (Tuxen 1970). The cupula (Figs 1, 2, 5-7) is a hymenopteran synapomorphy (Sharkey 2007) and is variable in form for ants. The anterior opening of the cupula is the foramen genitale (Fg, Figs 5-7; Schulmeister 2001), and is constricted to varying degrees across different lineages. In the ecitonines, the foramen genitale is reduced to 


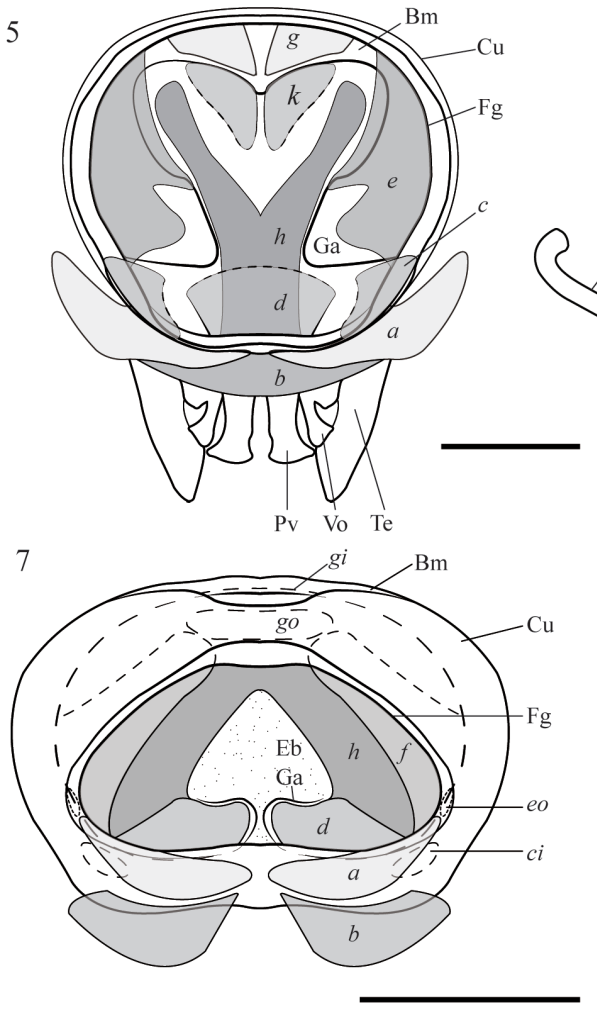

6

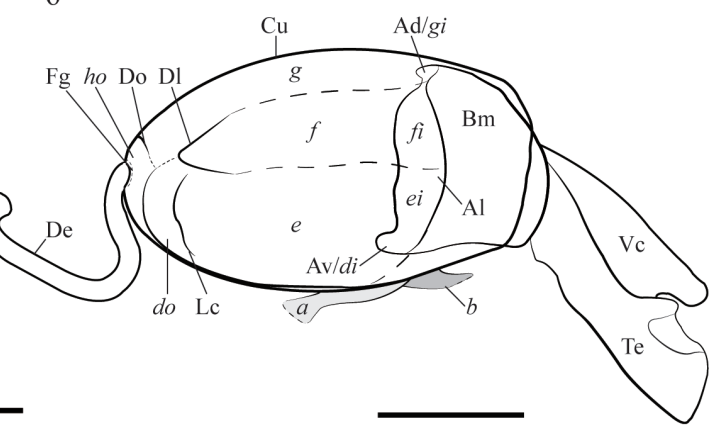

8

Figures 5-8. Muscles of the genital capsule and sternum IX. 5 Formica obscuripes genital capsule anterior-to-posterior view, $0.5 \mathrm{~mm} \mathbf{6}$ Neivamyrmex longiscapus lateral view, $1.0 \mathrm{~mm} 7$ Messor andrei genital capsule anterior-to-posterior view, $0.5 \mathrm{~mm} 8 \mathrm{~F}$. obscuripes volsella and paramere mesal view, with all penisvalvar muscles removed except $l, 0.5 \mathrm{~mm}$. Abbreviations: Ad anterodorsal apodeme of basimere; Al anterolateral apodeme of basimere; Ap apex gonostipitis; Av anteroventral apodeme of basimere; Ba basivolsellar apodeme; Bm basimere; Bv basivolsella; Cs cuspis; Cu cupula; Dl dorsolateral apodeme of cupula; Do dorsal apodeme of cupula; Eb endophallic bladder; Fg foramen genitale; Ga gonostipital arm; Lc lateral apodeme of cupula; Pv penisvalva; Te telomere; Vc valviceps; Vo volsella. Muscles: $a b c d$ efghijklp qrt; insertion of muscle ' $x$ ': $x i$; origin of muscle ' $x$ ': $x o$.

a miniscule aperture through which only the ductus ejaculatorius and tracheae pass (Fig. 6). In all ant taxa I examined, the ventral gonocondyle (Schulmeister 2003) of the cupula was absent.

Lateral to medial, the three paired valves are the parameres, volsellae, and penisvalvae (Figs 2 and 3). Homology of the parameres of the Formicidae with those of other Hymenoptera is reasonable, as the following complex characters are shared: 1) at least four of the five penisvalvae muscles attach to the basimeres; 2) an intrinsic muscle has an origin in the basimere and inserts in the telomere; and 3) a membrane is present at the telomere articulation with the basimere. It should be noted that this telomeral membrane is variable in development for the Formicidae, from well-developed to ab- 
9

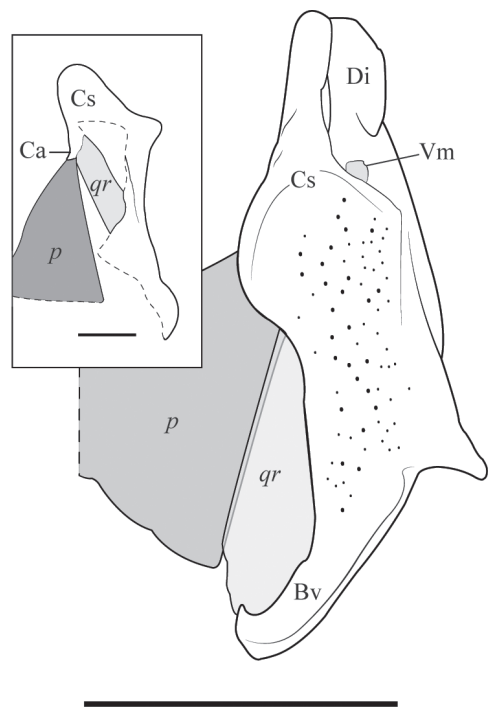

11

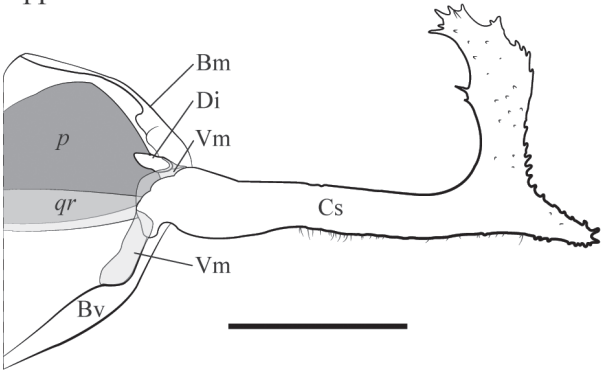

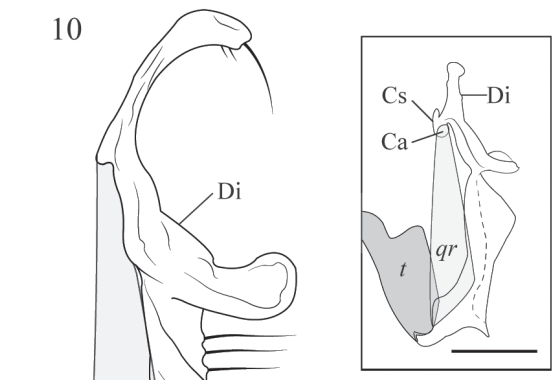

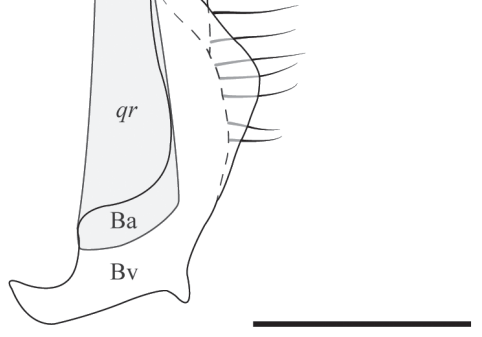

12

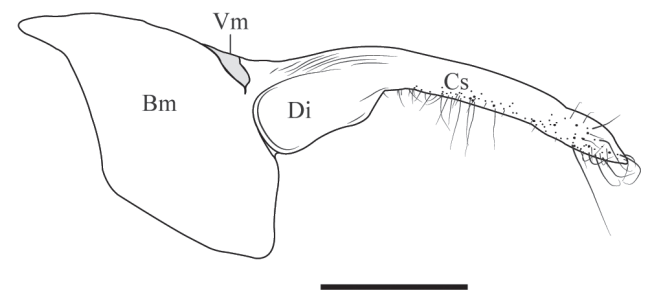

Figures 9-12. Volsella muscles and morphology; the parossiculus is composed of the basivolsella and distivolsella. 9 Formica obscuripes ventral view; inset mesal with digitus removed, dorsal left; both 0.5 $\mathrm{mm} 10$ Messor andrei mesal view, dash indicates base of twisted lamina and part of setose ridge; inset dorsal; both $0.2 \mathrm{~mm}$ I I Labidus coecus mesal view, $1.0 \mathrm{~mm}$ I 2 Neivamyrmex longiscapus lateral view, 0.5 $\mathrm{mm}$. Stippling on 9 and 12 indicate setal bases. Abbreviations: $\mathbf{B m}$ basimere; $\mathbf{B v}$ basivolsella; Ca cuspal apodeme; Cs cuspis; Di digitus; $\mathbf{V m}$ volsellar membrane. Muscles: $p q r t$, insertion of muscle ' $x$ ': $x i$; origin of muscle ' $x$ ': $x o$.

sent across numerous clades (Yoshimura and Fisher 2011). Thus the specific homology of the telomere with the basal hymenopteran harpe is dubious; therefore the application of "basimere" and "telomere" is preferable over "gonostipes" and "harpe" for ant genitalia. The parameres of ants are thus composed of a dish-like basimere and distal telomere (Figs 1 and 3). A ventromedial extension of the basimere is the origin site of several volsellar and penisvalvar muscles, and is termed the gonostipital arm (Ga, Fig. 8); this structure is not a synapomorphy of the Myrmicinae as claimed by Ogata (1991) because the gonostipital arm is present in other ant subfamilies (this study) and in many other hymenopteran lineages (Schulmeister 2001, 2003). The volsella, another hymenopteran synapomorphy along with the cupula (Sharkey 2007), is composed 


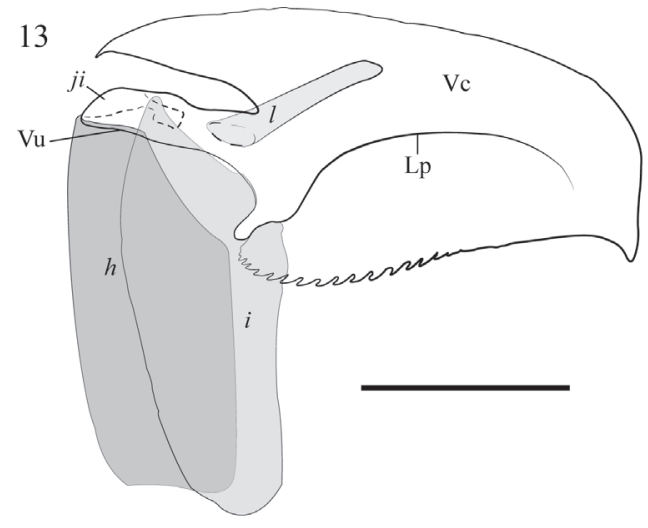

14
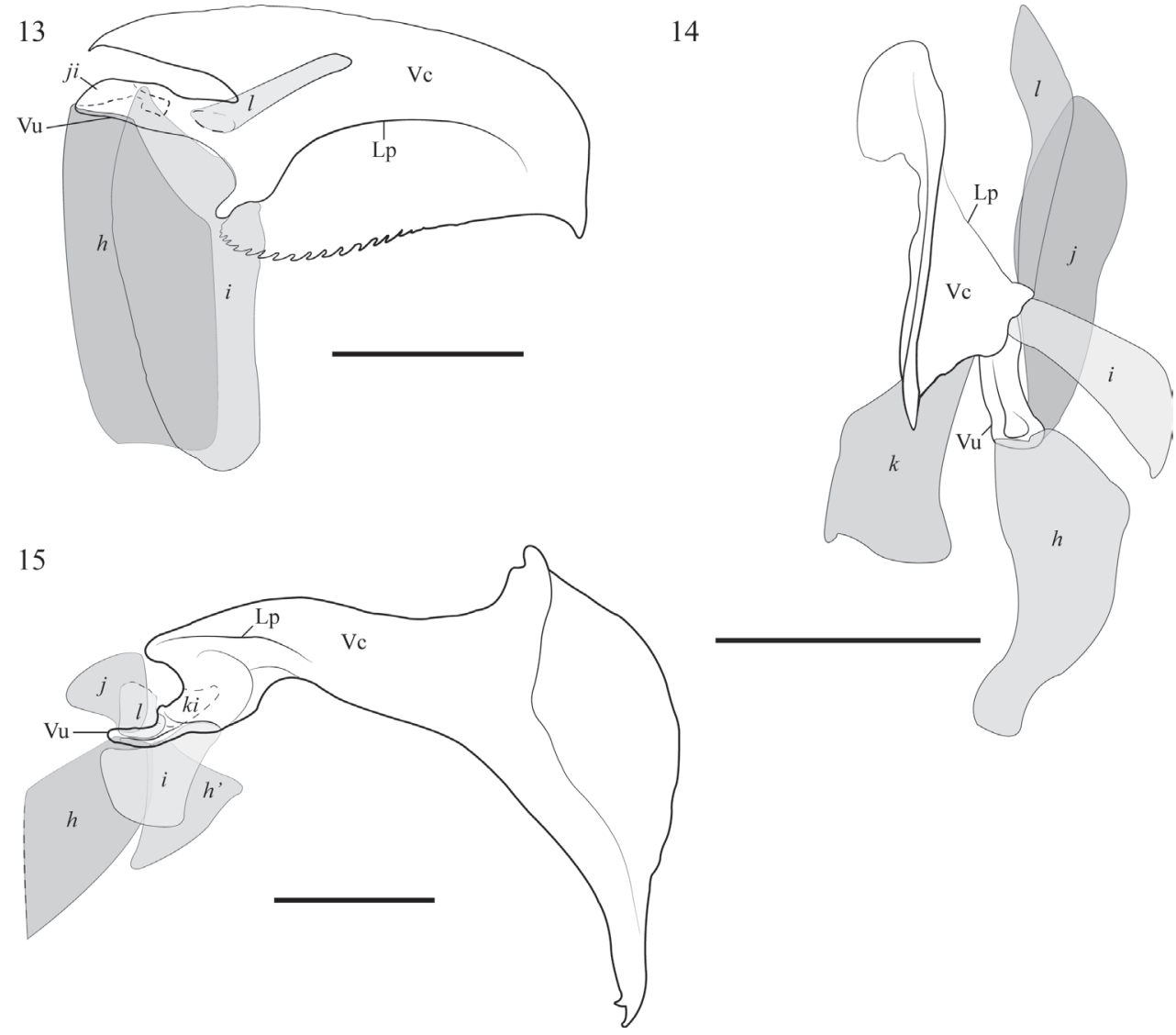

Figures 13-15. Penisvalva muscles and morphology. I 3 Formica obscuripes ectal view, $0.5 \mathrm{~mm} \mathbf{1 4}$ Messor andrei ventral, $0.2 \mathrm{~mm} 15$ Labidus coecus ectal view, $k i$ is on mesal face of valvura, $1.0 \mathrm{~mm}$. Abbreviations: Lp lateral apodeme of penisvalva; Vc valviceps; Vu valvura. Muscles: $h$ h' ${ }^{\prime} j$ k l; insertion of muscle ' $x$ ': $x i$; origin of muscle ' $x$ ': $x o$.

of the digitus which is basolaterally articulated with the parossiculus (Figs 8-12). The parossiculus is generally divided into the basivolsella and cuspis (= distivolsella, Figs 9-11). As the volsella is unique to the Hymenoptera, term preference is ambiguous; however, given that distivolsella has never been applied to Formicidae, I propose that "cuspis" be maintained. The cuspis is usually setose (Schulmeister 2001); this is indeed the case for all ant taxa examined (Cs, Figs 9-12).

Although the term aedeagus has a long history and is frequently used in the myrmecological literature to describe the middle-most valves (Brown Jr. 1960; Serna and Mackay 2009; Smith 1942; Taylor 1965; Yoshimura and Fisher 2012), this term is correctly applied to the whole intromittent apparatus which includes the sclerites, or penisvalvae, and the endophallus. The term "penisvalva" is preferred over "aedeagal plate" as the former term is virtually restricted to and broadly used for the Hymenoptera and represents the homology of the sclerite in question between ants and other 
hymenopterans, while the latter term is used for non-homologous structures among several insect orders ("penisvalva" e.g. Apoidea, Pesenko and Astafurova 2006; "Parasitica”, Karlsson and Ronquist 2012; Vespoidea and 'Symphyta', Schulmeister 2003; "aedeagal plate" e.g. Hemiptera: Rivers 1948; Diptera: Amorim 2007; Hymenoptera: Ogata 1987). The homologies of the cranially-directed apophysis and the distal component of the ant penisvalva with the valvura and valviceps are highly likely; the location and musculature of the apophysis are equivalent to those in the basal Hymenoptera and Aculeata (Schulmeister 2003). I thus adopt the terms valvura for the arm-like apophysis and valviceps for the distal component of the penisvalva (Figs 13-15; Schulmeister 2001). The penisvalvae are joined mediodorsally via a tough membrane (Pm, Figs 2 and 3), and an aedeagal gland is present in various forms between the valves (not figured; Hölldobler and Engel-Siegel 1982). A lower oblique carina (Ward 2001) is present in some taxa along the ectal face of the valviceps (Lp, Figs 13-15), forming a channel-like groove in formicines. Forbes (1952) hypothesized that the channel functions as a "sperm gutter"; this seems unlikely as the channel is separated from the phallotrema by the blade of the valviceps. I hypothesize that the lower oblique carina functions as an arch, transferring the force of the pensivalvar muscles to the valviceps apex.

\section{Internal genitalia (Figs 16 and 17)}

As the aedeagus is the interface between the internal and external genitalia, a general description of the internal genitalia is warranted (Fig. 16). Spermatozoa are produced in the follicles of the paired testes and pass through the vas deferens (Snodgrass 1935; Schulmeister 2001) into the vasicula seminalis where they are kept until copulation. The two vasiculae seminalae join together into the ductus ejaculatorius which opens into the endophallic bladder via the gonopore (Fig. 17; Snodgrass 1935). The endophallic bladder was formerly known as the aedeagal bladder, but it is definitely a component of the endophallus (Snodgrass 1935); its function remains unknown (Ball and Vinson 1984; Ball et al. 1984). A sclerite is present in the ductus ejaculatorius which has been identified as the fibula ducti in 'Symphyta' (Schulmeister 2003), the wedge in Neivamyrmex (We, Fig. 16; Forbes and Do-Van-Quy 1965) and sperrkeil in Formica rufa (translates contextually to keel-shaped valve, Clausen 1938). Although this sclerite was found in most taxa examined, it was not homologized across the Hymenoptera or among ant subfamilies as its morphology was not explicitly examined. The endophallus opens externally via the phallotrema at the bases or the dorsal apices of the penisvalvae (Pt, Fig. 3).

\section{Musculature}

The homology of genitalic musculature for each species examined is summarized in Table 2. Fifteen total muscles were observed among the examined ant taxa. Considerable variation exists in the morphology of tergites IX and X, but as these are not primary components of the genitalia these were excluded from this investigation. Three muscles, 

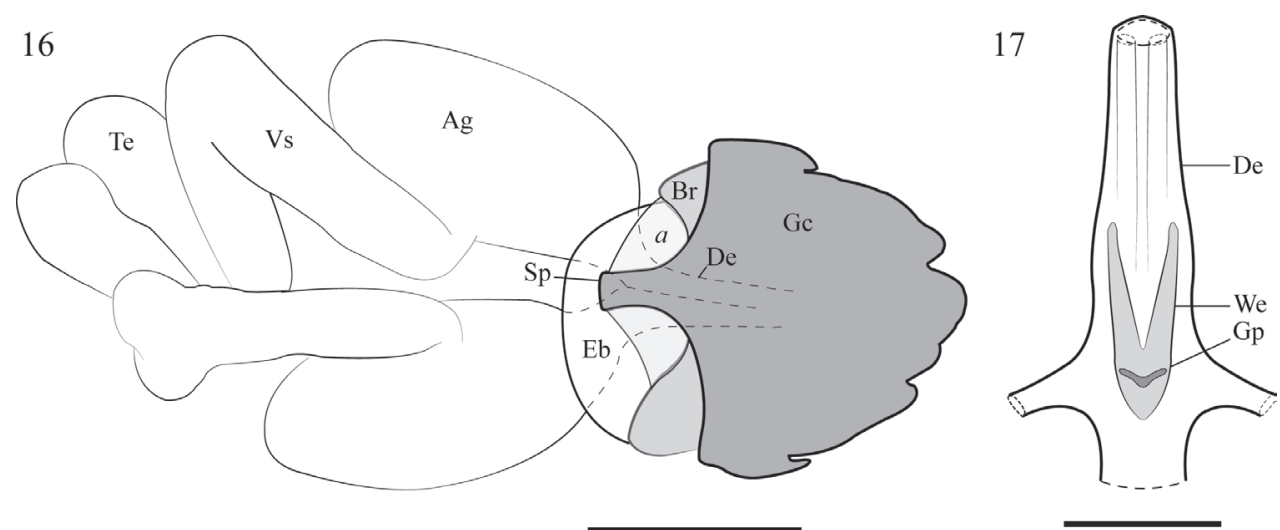

Figures 16-17. Internal genitalia. 16 Formica obscuripes ventral oblique view, $1.0 \mathrm{~mm} \mathbf{1 7}$ Labidus coecus ductus ejaculatorius with wedge sclerite ventral view, $0.5 \mathrm{~mm}$. Abbreviations: Vs vasicula seminalis; Ag accessory gland; De ductus ejaculatorius; Eb endophallic bladder; Gc genital capsule; Gp gonopore; Sp spiculum; Te testis; We wedge sclerite. Muscle: $a$.

$a, b$ and $c$, have their origins on sternum IX and insert on the cupula (Figs 4, 5-7). Muscle $a$ is paired and originates on the spiculum from which it diverges to the ventrolateral margin of the cupula, except in the ecitonines where $a$ is inserted in a median groove ventrad to the reduced foramen genitale. The origin of the unpaired muscle $b$ is along the cranial apodeme; the muscle converges anteriorly to its ectal insertion on the medioventral margin of the cupula. Each element of the paired muscle $c$ originates on an anterolateral lobe of the sternum and inserts on the ventrolateral margin of the cupula.

Four muscles, $d, e, f$, and $g$, have their origins on the cupula (Figs 1-3, 5-8). Muscles $e, f$, and $g$ are paired, while $d$ is unpaired. The origins of the cupula muscles are usually associated with an apodeme: muscle $d$ with the ventral, $e$ with the lateral, $f$ with the dorsolateral and $g$ with the dorsal apodeme (Figs 1, 2, 6). In general the gonostipital arms, or anteromedian projections of the basimeres, receive the insertions of $d$ on the ventral margin and $e$ ventrolaterally (Figs $1,5,7,8)$. Both $f$ and $g$ insert ectally on the basimere, $f$ on the lateral margin and $g$ on the dorsal margin (Figs 1-3, 5-8). Loss of cupula muscles was observed for three species: Atta cephalotes L. (1758), Crematogaster nigropilosa Mayr 1870, and Leptanilloides sp. in which the cupula is reduced to a thin strip with only muscle $e$ present. Muscles $f$ and $g$ are fused in Pheidole californica Mayr 1870, and muscle $d$ could not be confirmed for Hypoponera opacior Forel (1893), Odontomachus chelifer Latreille (1802), and Cerapachys nr. augustae.

In total, five penisvalva muscles (Figs 13-15) were found; $h, i, j$, and $k$ were consistently present except in the reduced genitalia of Leptanilloides sp. (Table 2), while $l$ was lost in disparate taxa. These muscles are paired, with one element of each associated with a left or right penisvalva. Three of the penisvalva muscle origins are on the mesal face of the basimere: $i$ on the ventral, $j$ on the dorsolateral, and $k$ on the dorsomedian face $(j, k$ Figs $1-3 ; i$ Fig. 8). The origin of muscle $h$ is variable, in some cases spanning the apices gonostipitum to the ventral apodeme of the cupula. Although the dorsome- 
Table 2. Muscle presence or absence per taxon. Only muscles recorded from the Aculeata are included. 0 absent; 1 present; 2 fused; ? presence/absence unconfirmed; ${ }^{\ddagger}$ Amblyoponinae; ${ }^{\S}$ Cerapachyinae; $\mid$ Dolichoderinae; ` Ecitoninae; ${ }^{\#}$ Ectatomminae; ${ }^{\dagger \dagger}$ Formicinae; ${ }^{{ }^{\ddagger}}$ Leptanilloidinae; ${ }^{\$ \varsigma}$ Myrmicinae; " Ponerinae; "Sphecidae and \# Vespidae (final two from Schulmeister 2003). Note: Myrmica kotokui data coded from Ogata (1991) in which the following muscles were mislabeled: $f, i, j, k, q r, t$.

\begin{tabular}{|c|c|c|c|c|c|c|c|c|c|c|c|c|c|c|c|c|}
\hline \multirow{2}{*}{ Species } & \multicolumn{16}{|c|}{ Muscles } \\
\hline & a & b & c & d & e & f & g & $\mathbf{h}$ & $\mathbf{i}$ & j & $\mathbf{k}$ & 1 & $\mathbf{o}$ & $\mathbf{p}$ & $\mathbf{q r}$ & $\mathbf{t}$ \\
\hline Prionopelta nr. modesta & 1 & 1 & 1 & 0 & 1 & 1 & 1 & 1 & 1 & 1 & 1 & 1 & 0 & 1 & 1 & 1 \\
\hline Cerapachys nr. augustae & 1 & 1 & 1 & $?$ & 1 & 1 & 1 & 1 & 1 & 1 & 1 & 1 & 0 & 1 & $?$ & 1 \\
\hline Cylindromyrmex brevitarsus & 1 & 1 & 1 & 0 & 1 & 1 & 1 & 1 & 1 & 1 & 1 & 1 & 0 & 1 & 0 & 1 \\
\hline Dolichoderus bispinosus & 1 & 1 & 1 & 1 & 1 & 1 & 1 & 1 & 1 & 1 & 1 & 1 & 0 & 1 & 1 & 1 \\
\hline Eciton lucanoides & 1 & $?$ & 1 & 1 & 1 & 1 & 1 & 1 & 1 & 1 & 1 & 1 & 0 & 1 & 1 & 0 \\
\hline Labidus coecus ${ }^{9}$ & 1 & 1 & 0 & 1 & 1 & 1 & 1 & 1 & 1 & 1 & 1 & 1 & 0 & 1 & 1 & 0 \\
\hline Labidus praedators & 1 & 1 & 0 & 1 & 1 & 1 & 1 & 1 & 1 & 1 & 1 & 1 & 0 & 1 & 1 & 0 \\
\hline Neivamyrmex longiscapus & 1 & 1 & 1 & 1 & 1 & 1 & 1 & 1 & 1 & 1 & 1 & $?$ & 0 & 1 & 1 & 0 \\
\hline Nomamyrmex eisenbeckit & 1 & 1 & 1 & 1 & 1 & 1 & 1 & 1 & 1 & 1 & 1 & 1 & 0 & 1 & 1 & 0 \\
\hline Gnamptogenys mordax ${ }^{\#}$ & 1 & 1 & 1 & 1 & 1 & 1 & 1 & 1 & 1 & 1 & 1 & 1 & 0 & 1 & 1 & 0 \\
\hline Camponotus sansabeanus ${ }^{\dagger \dagger}$ & 1 & 1 & 1 & 1 & 1 & 1 & 1 & 1 & 1 & 1 & 1 & 0 & 0 & 1 & 1 & 1 \\
\hline Camponotus atriceps ${ }^{\dagger \dagger}$ & 1 & 1 & $?$ & 1 & 1 & 1 & 1 & 1 & 1 & 1 & 1 & 0 & 0 & 1 & 1 & 1 \\
\hline Formica obscuripes ${ }^{\dagger \dagger}$ & 1 & 1 & 1 & 1 & 1 & 1 & 1 & 1 & 1 & 1 & 1 & 1 & 0 & 1 & 1 & 1 \\
\hline Prenolepis imparis ${ }^{\dagger \dagger}$ & 1 & 1 & 1 & 1 & 1 & 1 & 1 & 1 & 1 & 1 & 1 & 0 & 0 & 1 & 1 & 1 \\
\hline Leptanilloides sp. & 0 & 1 & 0 & 0 & 1 & 0 & 0 & 0 & 0 & 1 & 0 & 0 & 0 & 1 & 0 & 1 \\
\hline Aphaenogaster nr. rudis ${ }^{\S \S}$ & 1 & 1 & 1 & 1 & 1 & 1 & 1 & 1 & 1 & 1 & 1 & 1 & 0 & 0 & 1 & 0 \\
\hline Atta cephalotes ${ }^{\S \varsigma}$ & 1 & 1 & 1 & 0 & 1 & 1 & 1 & 1 & 1 & 1 & 1 & 1 & 0 & 0 & 1 & 0 \\
\hline Crematogaster nigropilosa $a^{\S \S}$ & 1 & 1 & 1 & 1 & 0 & 1 & 1 & 1 & 1 & 1 & 1 & 0 & 0 & 1 & 1 & 1 \\
\hline Messor andrei ${ }^{\$ S}$ & 1 & 1 & 1 & 1 & 1 & 1 & 1 & 1 & 1 & 1 & 1 & 1 & 0 & 0 & 1 & 1 \\
\hline Myrmica kotokui ${ }^{\S 5}$ & 1 & $?$ & 1 & 1 & 1 & 1 & 1 & 1 & 1 & 1 & 1 & $?$ & 0 & 1 & 1 & 1 \\
\hline Pheidole californica ${ }^{\S}$ & 1 & 1 & 1 & 1 & 1 & 2 & 2 & 1 & 1 & 1 & 1 & 0 & 0 & 0 & 1 & 0 \\
\hline Hypoponera opaciorl & 1 & 1 & 1 & $?$ & 1 & 1 & 1 & 1 & 1 & 1 & 1 & 0 & 0 & 0 & 1 & 0 \\
\hline Leptogenys donisthorpeil & 1 & 1 & 1 & 1 & 1 & 1 & 1 & 1 & 1 & 1 & 1 & 1 & 0 & 1 & 1 & 0 \\
\hline Odontomachus cheliferl & 1 & 1 & 1 & $?$ & 1 & 1 & 1 & 1 & 1 & 1 & 1 & 1 & 0 & 1 & 1 & 0 \\
\hline Platythyrea prizo" & 1 & 1 & 0 & $?$ & 1 & 1 & 1 & 1 & 1 & 1 & 1 & 1 & 0 & 1 & 1 & 0 \\
\hline Sceliphron caementarum ${ }^{99}$ & 0 & 1 & 0 & 0 & 1 & 1 & 1 & 1 & 1 & 1 & 1 & 1 & 1 & 1 & 0 & 0 \\
\hline Dolichovespula adulterina & 0 & 1 & 0 & 1 & 1 & 0 & 1 & 1 & 1 & 1 & 1 & 1 & 1 & 1 & 1 & 0 \\
\hline
\end{tabular}

dial basimeral area where $k$ originates has been termed the parapenis in basal Hymenoptera (Schulmeister 2001), this term is not used for the Formicidae due to uncertain homology. Muscle $l$ has its origin on the basal dorsomedian area of the telomere (Figs 3 and 8). The insertions of $h$ and $j$ are on the ventral and dorsal faces of the valvura apices, respectively. Muscles $i$ and $l$ are inserted on the penisvalva lateral apodeme (Figs 13-15; Ward 2001), an equivalent structure to the ergot of basal hymenoptera (Schulmeister 2001). Finally, $k$ is mesally inserted on the base of the valvura or the valviceps (Fig. 15). 
Across the taxa examined there was great variation in the form of the volsellae, with concomitant variation in the presence and form of the two muscles, $p$ and $q r$ (Figs 9-11) which both insert on the cuspal apodeme. Similar to the penisvalvar muscles, the volsellar muscles are paired with one element of each associated with a left or right volsella. Muscles $m, n, o, s$, and $s i$ (Schulmeister 2001) were not present in the examined taxa, and were presumably lost in the ancestral ant lineage or earlier. Muscle $p$ has its origin on the internal lateral face of the basimere. Reduction of the cuspis and loss of $p$ was observed in Aphaenogaster nr. rudis, Messor andrei, Pheidole californica and Hypoponera opacior. This contrasts with the intrinsic volsellar muscle qr which was present in all but two taxa examined, and could not be confirmed for a third. The origin on $q r$ is on the basivolsellar apodeme.

A single intrinsic muscle of the paramere, $t$, was found in several of the taxa examined. Muscles $u$ and $v$ (Schulmeister 2001) were never present. Muscle $t$ is paired, with the left or right element originating anterolaterally on the respective basimere (Fig. 8) and inserting on the telomeral corium (Fig. 1). Presence of $t$ was inconsistent; in the present dataset, loss is associated with telomere fusion to the basimere, in reduced genitalia, and with change in telomere function. In these circumstances, other muscles including the volsellar $p$ and penisvalvar $j$ are hypothesized to affect the grasping capacity of the parameres via elastic forces.

\section{Functional morphology}

\section{Formica obscuripes Forel, 1886}

Among the taxa examined this species has relatively generalized genitalia, with all fifteen muscles present and without extreme modifications of the sclerites. The three muscles of sternum IX, $a, b$, and $c$, are present in this species (Figs 4 and 5). Simultaneous contraction of both elements of $a$ contracts the genital capsule into the gaster to varying degrees. Antagonistic contraction of either the left or right element of $a$ adducts the genital capsule towards the respective side, an action which is synergistic with the genital capsule protractor $b$. Muscle $c$ inserts ventrolaterally on the ventral apodeme of the cupula, above the insertions of $a$ and $b$ (Fig. 5), and torques the genital capsule via elevation of the basal margin of the cupula toward the muscle's origin.

Muscles of the cupula rotate the genitalic valves within the cupula similarly to a ball-in-socket mechanism. Each muscle is inserted on the anterior margin of the basimere except for $d$, which inserts on the anteroventral face of the endophallic bladder (Figs 5 and 8). Muscle $e$ adducts the valves ventrally, while $g$ acts antagonistically to elevate the apices while contracting the valves. Muscle $e$ also adducts the telomere to the mediosagittal plane by drawing the medioventral apices of the basimeres dorsolaterally. Contraction of $f$ may affect torsion of the valves.

All five muscles of the penisvalvae are present in this species (Fig. 13). The penisvalvae can move independently along the mediosagittal plane and are capable of rotation, 
pivoting on their lateral apodemes. Elevation of the valviceps is caused by contraction of $h$, while depression is caused by $j$. Muscle $k$ is inserted basally on the valviceps and may dig the basal teeth into the female's bursa copulatrix (Kamimura 2008) by drawing the valviceps anterad and adducting the apices ventrally. Rhythmic contraction of $i$ may enhance this hypothetical function in order to gain greater purchase in the female via a motion analogous to mastication. Muscle $l$ abducts the valviceps ventrolaterally swinging the apices apart, potentially to allow passage of ejaculate during copulation or to remove the sharply curved valviceps teeth from the female.

Two muscles, $p$ and $q r$, are attached ectally and mesally to the cuspal apodeme of the volsellae, respectively, and act antagonistically to open or close the cuspides (Fig. 9). Adduction of the cuspis to the digitus is caused by contraction of $q r$, which bends the volsellar plate toward the penisvalvae while drawing the cuspal apex toward the digitus. The antagonistic abduction of the cuspis is induced by $p$, which extends laterally to the basimere from the ectal face of the cuspal apodeme (Figs 8 and 9).

The single intrinsic muscle of the paramere, $t$, is relatively well developed in this species. Contraction of $t$ flexes the telomere ventrally via folding of the telomere cori$\mathrm{um}$. Upon relaxation of $t$, the elastic force of the sclerotic bridge between the basimere and telomere sclerite erects the telomere. Flexion of the telomere may also be affected by the penisvalvar muscle $j$ which has a major portion of its origin along a mediodorsal inflection of the basimere. Intense contraction of $j$ may roll the telomere ventrally via torsion of the inflection ectally, while also flexing the penisvalvae ventrally; this may function to strengthen the clamp-hold of the female.

\section{Messor andrei Mayr, (1886)}

With the loss of $p$, fourteen of the fifteen genitalic muscles are found in this species. Although the foramen genitale is somewhat constricted (Fg, Fig. 7), the muscular function of the cupula and sternum IX are not distinct enough from Formica obscuripes to warrant separate discussion. The clasping function of the paramere is maintained despite the replacement of most of the telomere corium by sclerite. In this case, there is very little telomere flexion. Rather, $t$ adducts the apices of the telomere toward the mediosagittal plane while pulling the medioventral faces dorsally. The mesal face of the telomere has a cup-like lamina which, coupled with hypothetical secretions of the telomeral gland, may enhance the male's grasp on the female.

The valviceps is produced dorsally with a laterally-produced lamina (Lm, Fig. 2) which is divided into anterior and posterior lobes by a constriction, making the valviceps similar in shape to an anvil. The dorsal laminae may function as a passive anchor in the female's bursa copulatrix while the aedeagus is intromittent. Between the two valviceps, an ellipsoid chamber is formed with the penisvalvar membrane closing it dorsally. I hypothesize that this chamber acts as a mechanical sperm pump, forcefully pulsing ejaculate out of the anterior-directed phallotrema via contraction of $l$, which spreads the valviceps bases. Contraction of $j$ may synergistically contribute to this hypothetical action via rotation around a vertical axis placed at the dorsal constriction, 
drawing the dorsal posterior lobes together while spreading the anterior lobes and valviceps apices ectally. Muscle $j$ also adducts the valviceps ventrally. The basal wall of the valviceps, where $k$ is inserted, is inflected dorsally and ventrally into a rough parabola with its vertex pointed anteriorly. This inflection divides $k$ into dorsal levator and ventral contractor halves. Motion of $l$ and $k$ together may pull the valviceps anteroventrally, potentially digging the valviceps teeth into the female. Muscle $h$ has most, if not all, of its origin along the endophallic bladder.

Clasping is not the function of this species' modified volsella (Fig. 10), since the digitus is completely fused with the setose cuspal shaft, and is in the form of a crescent with a basal flange and apical process. The apical component of the cuspis is reduced to a small ellipsoid plate that articulates with the digitus laterally (Cs, Fig. 10, inset). Muscle $p$ has been functionally replaced by $q r$ which is divided into dorsal and ventral halves by the flange-like basivolsellar apodeme (Ba, Fig. 10). The dorsal margin of the cuspis is produced into a lamina which twists $-180^{\circ}$ around the basal-distal axis. The reduced cuspis apex acts as a pivot for rotation of the digital crescent, while the twisted lamina provides strength and elastic flexibility for torsion of the volsella. Ventral contraction of $q r$ in the left volsella rotates the apex of the digitus medioventrally clockwise, while dorsal contraction rotates the digital flange dorsolaterally counterclockwise. Thus $q r$ has a fine-tuned forward and reverse function via differential contraction of the dorsal or ventral sides coupled with the elastic torsion of the cork-screw cuspis. The copulatory function is hypothesized to be prying the terminal plates of the female open, akin to a lock-pick, via insertion of either the digitus or digital flange into the female followed by lifting or depressing torsion.

Labidus coecus Latreille, (1802)

The genitalia of Labidus have been greatly modified in form relative to the nonecitonine taxa examined. Sternum IX is produced apically into a bifid lobe and muscle $c$ is absent. An external longitudinal groove extends along the ventral face of the egg-shaped cupula ( $\mathrm{Cu}$, Fig. 8) and receives the insertions of muscles $a$ and $b$. The origin of $b$ has migrated up the anterolateral lobes of the sternum; the muscle extends mesally to its insertion in the ventral groove just posterad the insertion of $a$, which is ventrad the foramen and is longitudinally elongated. This elongation of $a$ along the curvature of the cupula prevents pronounced dorsal or ventral pitch during contraction of $a$. Muscle $b$ may either torque the capsule contralaterally with contraction of the left or right half, or both halves together may adduct the apices of the genital valves ventrally.

Contrary to the arguments of Birket-Smith (1981), I found the cupula muscles of Labidus to have clear homology with the pleisiomorphic muscles $d$, $e, f$, and $g$ (Fig. 4). Birket-Smith (1981) suggests that muscles $e, f$ and $g$ have been lost during the evolution of Labidus to be replaced by a "vaguely differentiated muscle, $d$.'" I disagree with this interpretation: the muscular origins are identical with respect to association with cupula apodemes (Do, Dl, Lb, Fig. 4) while the muscles themselves are distinguish- 
able by seams between the bundles. Moreover, the insertions on the apodemes of the basimeres are relatively distinct (Ad, Ac, Av, Fig. 6), especially that of $g$ which is broadest medially and tapers laterally. The lateral basimere apodeme is emarginate between the insertion of $f$ on the dorsal and $e$ on the ventral half. Muscle $d$ is inserted on a cranially-directed anteroventral process of the gonostipital arm.

Contraction of the cupula muscles may cause splaying and movement in the mediosagittal plane. The cupula of all ecitonine species investigated is extremely strong and well-constructed to withstand the forces applied to it internally. A tall longitudinal apodeme is present along most of the length of the ring, from the foramen genitale to the apices gonostipitum. This apodeme may function as a strut, strengthening the cupula from the antero-posterior compression forces exerted by the cupular muscles. The anteroventral processes of the basimeres are extended anteriorly to a greater magnitude than the dorsal margins of the basimeres. Thus the dorsal margins of the basimeres act as a fulcrum for a third-order lever: synergistic contraction of $d$ and $e$ act as in-forces and cause the apices of the genitalic valves to swing ventrally. As muscle $e$ converges mesally from its ventrolateral origin, it may also be able to fine-tune the yaw of the adduction motion. Muscle $f$ contributes primarily to the spreading of the genitalic valves around a vertical axis of rotation between the apices gonostipitum and the bases of the valviceps.

With respect to the penisvalva muscles, Birket-Smith (1981) discussed a muscle he termed $h$ '. This is not a novel muscle; rather it is the well-developed posterior portion of muscle $h$ which extends into the basimere. This portion may be seen in several other taxa, including Formica obscuripes in which $h$ is not fully divided. Muscle $k$ has the typical origins and insertions on the dorsal anteromedian faces of the basimeres (Fig. 3) and mesal face of the valvurae (Fig. 15). Muscle $h$ has its origin across the length of the cupula on the cupula's anterior wall, opposite the insertion of $a$. The origin of $i$ extends from the ventromedial to the anterolateral face of the basimere. This lateral projection was interpreted by Birket-Smith (1981) to be the only component of $i$. Comparison with Formica obscuripes again clarifies the homology, as muscle $i$ of the formicine may be seen to extend to the lateral face of the basimere as well.

Four of the five penisvalva muscles seem to act synergistically by contributing forces to the ventral adduction of the penisvalva apex, while only $h$ acts antagonistically. The muscles all act as in-forces for moving the penisvalva as a lever and may be conveniently grouped by the order of their lever mechanism: muscle $h$ as first-order dorsal adductor; muscles $k$ and $j$ as first-order and $i$ as a third-order ventral adductor. Besides contributing to ventral or dorsal adduction, $h$ antagonistically closes or spreads the ventral apices of the penisvalvae.

The volsellae of Labidus are highly modified, which has led to confusion of their homology (Birket-Smith 1981; Brady and Ward 2005; Watkins II 1982). The entire organ has migrated to a ventral position beneath the penisvalvae (Fig. 3), and the stalked distal element hinges ventrally on the reduced basivolsella which is completely fused with the basimere. In the literature, the distal element of the volsella has been termed the digitus: it is clear that this is not the case. The true digitus is a small ellipsoid plate, hitherto unreported, attached to the volsellar corium in a dorsolateral 
position at the base of the distal element (Di, Fig. 11). Moreover the distal volsellar element is setose, a character state associated solely with the cuspis and potentially a deep autapomorphy for the Hymenoptera (Schulmeister 2001; Sharkey 2007). As a corollary, the digitus of Neivamyrmex longiscapus Borgmeier 1953 is retained as a rounded quadrangular plate fused with the shaft of the cuspis (Di, Fig. 12), while that of Nomamyrmex eisenbeckii Borgmeier 1936 is reduced and completely fused with the cuspal shaft.

Both muscles of the volsellae are present (Fig. 11), with their insertions on the cuspal apodeme. Birket-Smith (1981) identified the cuspal muscles $r$ and $s$. As neither $r$ nor $s$ are present in any of the other taxa examined, it is most parsimonious at present to recognize them as $p$ and $q r$, respectively. The origin of muscle $p$ covers a large area within the basimere laterally to dorsolaterally, while the origin of $q r$ has migrated from its position on the basivolsellar apodeme to the basimeral anterolateral region. The movements of the cuspis were difficult to ascertain. However, the muscles may act antagonistically to elevate or depress the cuspis. During depression of the cuspis, the cuspal condyle slides ventrally along a vertical shelf of the basimere until it strikes a medially-projected shelf. Because this shelf has a margin contour complementary to the basal swelling of the cuspis, the basal swelling may be pulled into the volsellar corium, potentially providing torque to the cuspis. The copulatory function of these modified volsellae is not known; nor is it known whether they are intromittent.

The final point of contention with Birket-Smith's (1981) description of the musculature of Labidus is the muscle of the telomere. From my dissections of Labidus, I found that when a telomere was not carefully disarticulated, a small muscle fragment could be found with its insertion on the medial face of its base, suggesting the presence of a unique muscle specific to the telomere. It became clear, however, after more care was taken that this was actually $l$, and that its insertion on the valvura could be observed. I thus conclude that Birket-Smith's putative muscle $y$ is actually muscle $l$, and that no novel muscle has evolved in the telomeres of Labidus. The telomere is restricted to lateral movement as the medial base is fused to the basimere via sclerotization, while the rest of the telomere base is surrounded by membrane (Tm, Fig. 3). The differential flexibility of the sclerotic bridge and the corium swing the telomeres laterally when $j$ is contracted, with the bridge acting as a pivot. Thus the grasping function of the telomeres of Labidus and other ecitonines has been lost, excepting Nomamyrmex.

\section{Conclusion}

The intersubfamilial homology of male ant genitalic musculature is described for the Amblyoponinae, Cerapachyinae, Dolichoderinae, Ectatomminae, Formicinae, Leptanilloidinae, Myrmicinae and Ponerinae for the first time, while the musculature and sclerite homology of the ecitonines Labidus and Neivamyrmex are clarified. Overall, the generalized male ant has fifteen muscles: three on sternum IX, four on the cupula, 
five penisvalvar, two volsellar and one paramere muscle. Muscles of sternum IX act to protract, contract or torque the genitalic capsule, which may aide in probing and intromittent behavior. The cupula muscles attach to the basimeres, and are most variable in presence or absence among the myrmicine taxa examined. Muscles of the cupula exert greater control over the genitalic valves relative to the muscles of sternum IX. The penisvalva muscles have functions which vary with the lineage, and muscle $l$ is lost in some. In general, the penisvalva muscles may torque the penisvalvae apices, while adducting the individual penisvalvae in the mediosagittal plane. Volsellar mechanics varies greatly with the morphology of the volsellar sclerites. In species with opposable digiti and cuspides, the muscles may spread or close the apices. In other species, the digiti may torque clockwise or counter-clockwise, while movement in Labidus is restricted to the mediosagittal plane. Finally, the parameres have a single muscle which is lost in some lineages to be replaced by any of the proximal muscles.

The mechanics of the sclerites and their muscles are labile over evolutionary time: the axes of rotation, the pivots, and the muscular origins and insertions shift across the sclerites. Detecting the patterns of morphological and mechanical evolution of male ant genitalia may provide useful phylogenetic characters, especially for clades currently with few or without morphological synapomorphies (e.g. the Formicoid clade, Ward 2011). Future studies should include representative taxa of each subfamily where males are known, emphasizing the differences among lineages. The hypertrophic genitalia of the Leptanillinae (Bolton 1990) provide an especially enticing opportunity, while the volsellar morphology of dorylomorphs (Brady and Ward 2005) may be valuable to reconsider, especially with musculature characters. A context and critical comparison of genitalic sclerites and muscles with the Vespoidea would be valuable and may potentially clarify the phylogenetic position of the Formicidae. Investigations of the mechanical processes involved in ant copulation will aid in understanding of the adaptations of the musculature and valves. Furthermore, we may use male genitalic musculature to predict evolutionary trends in behavior and reproductive biology. A foundation for interpreting genitalic musculature allows for neuroethological investigations with which comparative copulatory procedures may be experimentally observed (Kumashiro and Sakai 2001). The ground is set for describing the sequence and fine-scale interaction of the genitalic muscles on the male sclerites.

\section{Acknowledgments}

Thanks to my mentor Jack (John) T. Longino (University of Utah) for inspiration and review of this manuscript. For further reviews which improved the manuscript, I thank Marek L. Borowiec (University of California, Davis), Masashi Yoshimura (California Academy of Sciences), Erik V. Thuesen (the Evergreen State College, TESC), and two anonymous reviewers. Thanks to Eli M. Sarnat (University of Illinois), Erik B. Ordway (TESC) and Trisha Towanda (University of Rhode Island) for providing Adobe Illustrator assistance. This work was supported in part by the National Science Foundation 
grants DEB-0640015/DEB-1157383 and DEB-0072702 for the LLAMA and ALAS projects, respectively.

\section{References}

Acebes A, Cobb M, Ferveur JF (2003) Species-specific effects of single sensillum ablation on mating position in Drosophila. The Journal of Experimental Biology 206: 3095-3100. doi: $10.1242 / \mathrm{jeb} .00522$

Allard D, Gobin B, Ito F, Tsuji K, Billen J (2002) Sperm transfer in the Japanese queenless ant Diacamma sp. (Hymenoptera: Formicidae). Netherlands Journal of Zoology 52: 77-86. doi: $10.1163 / 156854202760405203$

Allard D, Børgesen L, Van Hulle M, Bobbaers A, Billen J, Gobin B (2006) Sperm transfer during mating in the pharaoh's ant, Monomorium pharaonis. Physiological entomology 31: 294-298. doi: 10.1111/j.1365-3032.2006.00519.x

Amorim DDS (2007) Two new genera of Swammerdamellini (Diptera, Scatopsidae), with a discussion of the position of the species of Rhexoza. Zootaxa 1640: 41-53.

Ball DE, Williams HJ, Vinson SB (1984) Chemical analysis of the male aedeagal bladder in the fire ant, Solenopsis invicta Buren. Journal of the New York Entomological Society 92: 365-370. doi: 10.1016/0020-7322(84)90003-5

Ball DE, Vinson SB (1984) Anatomy and histology of the male reproductive system of the fire ant Solenopsis invicta Buren (Hymenoptera: Formicidae). International Journal of Insect Morphology and Embryology 13: 283-294.

Baer B (2011) The copulation biology of ants (Hymenoptera: Formicidae). Myrmecological News 14: 55-68.

Baer B, Boomsma JJ (2006) Mating biology of the leaf-cutting ants Atta columbica and A. cephalotes. Journal of Morphology 267: 1165-1171. doi: 10.1002/jmor.10467

Birket-Smith SJR (1981) The male genitalia of Hymenoptera-a review based on morphology in Dorylidae (Formicoidea). Entomologica Scandinavica 15: 377-397.

Bolton B (1990) The higher classification of the ant subfamily Leptanillinae (Hymenoptera: Formicidae). Systematic Entomology 15: 267-282. doi: 10.1111/j.1365-3113.1990. tb00063.x

Bolton B (1995) A New General Catalog of the Ants of the World. Harvard University Press, Cambridge, 504 pp.

Boomsma JJ, Baer B, Heinze J (2005) The evolution of male traits in social insects. Annual Review of Entomology 50: 395-420. doi: 10.1146/annurev.ento.50.071803.130416

Boulangé H (1924) Recherches sur l'appareil copulateur des Hyménoptères et spécialement des Chalastogastres. Mémoires et Travaux de la Faculté Catholique de Lille 28: 1-444.

Brady SG, Ward PS (2005) Morphological phylogeny of army ants and other dorylomorphs (Hymenoptera: Formicidae). Systematic Entomology 30: 593-618. doi: 10.1111/j.13653113.2005.00290.x

Brown Jr W (1960) Contributions toward a reclassification of the Formicidae. III. Tribe Amblyopini (Hymenoptera). Bulletin of the Museum of Comparative Zoology 122: 145-230. 
Clausen R (1938) Untersuchungen über den männlichen Copulationsapparat der Ameisen, speziell der Formicinae. Mitteilungen der schweizerischen entomologischen Gesellschaft 17: 233-246.

Córdoba-Aguilar A, Uhía E, Rivera AC (2003) Sperm competition in Odonata (Insecta): the evolution of female sperm storage and rivals' sperm displacement. Journal of Zoology 261: 381-398. doi: 10.1017/S0952836903004357

Eberhard WG (2010) Rapid divergent evolution in genitalia: theory and data updated. In: Leonard JL, Córdoba-Aguilar A (Eds) The evolution of primary sexual characters in animals. Oxford University Press (New York): 40-79.

Eberhard WG, Gelhaus J (2009) Genitalic stridulation in a male tipulid fly. Revista de Biología Tropical 57: 251-256.

Fisher BL (2009) Two new dolichoderine ant genera from Madagascar: Aptinoma gen. n. and Ravavy gen. n. (Hymenoptera: Formicidae). Zootaxa 2118: 37-52.

Flowers RW, Eberhard WG (2006) Fitting together: copulatory linking in some Neotropical Chrysomeloidea. Revista de Biología Tropical 54: 829-842.

Foitzik S, Heinze J, Oberstadt B, Herbers JM (2002) Mate guarding and alternative reproductive tactics in the ant Hypoponera opacior. Animal Behaviour 63: 597-604. doi: 10.1006/ anbe. 2001.1945

Forbes J (1952) The genitalia and terminal segments of the male carpenter ant, Camponotus pennsylvanicus Degeer (Formicidae, Hymenoptera). Journal of the New York Entomological Society 60: 157-171.

Forbes J, Hagopian M (1965) The male genitalia and terminal segments of the ponerine ant Rhytidoponera metallica F. Smith (Hymenoptera: Formicidae). Journal of the New York Entomological Society 73: 190-194.

Forbes J (1967) The male genitalia and terminal gastral segments of two species of the primitive ant genus Myrmecia (Hymenoptera: Formicidae). Journal of the New York Entomological Society 75: 35-42.

Forbes J, Do-Van-Quy D (1965) The anatomy and histology of the male reproductive system of the legionary ant, Neivamyrmex harrisi (Haldeman) (Hymenoptera: Formicidae). Journal of the New York Entomological Society 73: 95-111.

Francoeur A, Loiselle R (1988) The male of Leptothorax wilda with notes on the subgenus Nesomyrmex (Formicidae, Hymenoptera). In: Arnett D (Ed.) Advances in Myrmecology. Brill, New York, 43-54.

Gorb SN (2008) Biological attachment devices: exploring nature's diversity for biomimetics. Philosophical transactions: Material, Physical and Engineering Sciences 336: 1557-1574. doi: $10.1098 /$ rsta.2007.2172

Hölldobler B, Engel-Siegel H (1982) Tergal and sternal glands in male ants. Psyche 89: 113-132. Hölldobler B, Wilson EO (1990) The Ants. The Harvard University Press, Oxford, 732 pp.

Hughes WOH, Boomsma JJ (2007) Genetic polymorphism in leaf-cutting ants is phenotypically plastic. Proceedings of the Royal Society B 274: 1625-1630. doi: 10.1098/ rspb.2007.0347

Kamimura Y (2007) Twin intromittant organs of Drosophila for traumatic insemination. Biology Letters 3: 401-404. doi: 10.1098/rsbl.2007.0192 
Kamimura Y (2008) Copulatory wounds in the monandrous ant species Formica japonica (Hymenoptera, Formicidae). Insectes Sociaux 55: 51-53. doi: 10.1007/s00040-007-0968-z

Keller RA (2011) A phylogenetic analysis of ant morphology (Hymenoptera: Formicidae) with special reference to the Poneromorph subfamilies. Bulletin of the American Museum of Natural History 335: 1-90. doi: 10.1206/355.1

Kumashiro M, Sakai M (2001) Reproductive behaviour in the male cricket Gryllus bimaculatus DeGeer. The Journal of Experimental Biology 204: 1123-1137.

LaPolla JS (2004) Acropyga (Hymenoptera: Formicidae) of the world. Contributions of the American Entomological Institute 33: 1-130. doi: 10.1111/j.1365-3113.2011.00605.x

LaPolla JS, Kallal RJ, Brady SG (2012) A new ant genus from the Greater Antilles and Central America, Zatania (Hymenoptera: Formicidae) exemplified the utility of male and molecular systems. Systematic Entomology 37: 200-214.

Ogata K (1987) A generic synopsis of the Poneroid complex of the family Formicidae in Japan (Hymenoptera). Part I. Subfamilies Ponerinae and Cerapachyinae. Esakia 25: 97-132.

Ogata K (1991) A generic synopsis of the Poneroid complex of the family Formicidae in Japan (Hymenoptera). Part II. Subfamily Myrmicinae. Bulletin of the Institute of Tropical Agriculture Kyushu University 14: 61-149.

Pesenko YA, Astafurova YV (2006) Contributions to the halictid fauna of the eastern Palearctic region: subfamily Rophitinae (Hymenoptera: Halictidae). Entomofauna Zeitschrift für Entomologie 27: 317-356.

Rivers IL (1948) A new species of Pelocoris from Nevada, with notes on the genus in the United States (Hemiptera: Naucoridae). Annals of the Entomological Society of America 41: 371-376.

Robertson HG, Villet M (1989) Mating behaviour in three species of myrmicine ants (Hymenoptera: Formicidae). Journal of Natural History 23: 767-773. doi: 10.1080/00222938900770401

Robinson GE, Page Jr RE (1989) Genetic determination of nectar foraging, pollen foraging, and nest-site scouting in honey bee colonies. Behavioral Ecology and Sociobiology 24: 317-323. doi: 10.1007/BF00290908

Ross KG (1982) Laboratory studies of the mating biology of the Eastern yellowjacket, Vespula maculifrons (Hymenoptera: Formicidae). Journal of the Kansas Entomological Society 56: 523-537.

Schulmeister S (2001) Functional morphology of the male genitalia and copulation in lower Hymenoptera, with special emphasis on the Tenthredinoidea s. str. (Insecta, Hymenoptera, 'Symphyta'). Acta Zoologica 82: 331-349. doi: 10.1046/j.1463-6395.2001.00094.x

Schulmeister S (2003) Genitalia and terminal abdominal segments of male basal Hymenoptera (Insecta): morphology and evolution. Organisms Diversity and Evolution 3: 253-279. doi: 10.1078/1439-6092-00078

Serna F, Mackay W (2010) A descriptive morphology of the ant genus Procryptocerus (Hymenoptera: Formicidae). Journal of Insect Science 10: 1-36. doi: 10.1673/031.010.11101

Sharkey MJ (2007) Phylogeny and classification of Hymenoptera. Zootaxa 1668: 1-766.

Smith MR (1942) The legionary ants of the United States belonging to Eciton subgenus Neivamyrmex Borgmeier. American Midland Naturalist 27: 537-590. doi: 10.2307/2420913 
Sueur J, Mackie D, Windmill JFC (2011) So small, so loud: extremely high sound pressure level from a pygmy aquatic insect (Corixidae, Micronectinae). PLoS ONE 6: e21089. doi: 10.1371/journal.pone.0021089

Snodgrass RE (1935) Principles of Insect Morphology. Comstock Publishing Associates, London, 667 pp.

Song H, Bucheli SR (2010) Comparison of phylogenetic signal between male genitalia and non-genital characters in insect systematics. Cladistics 26: 23-35. doi: 10.1111/j.10960031.2009.00273.x

Taylor RW (1965) A monographic revision of the rare tropicopolitan ant genus Probolomyrmex Mayr (Hymenoptera: Formicidae). Transactions of the Royal Entomological Society of London 117: 345-365. doi: 10.1111/j.1365-2311.1965.tb00044.x

Tuxen SL (1970) Taxonomist's glossary of genitalia in insects. Munksgaard, Copenhagen, 359 pp.

Villet MH (1999) Reproductive behaviour of Plectroctena mandibularis F. Smith (Hymenoptera: Formicidae), a ponerine ant with ergatoid queens. African Entomology 7: 289-291.

Walker Jr WF, Liem KF (1994) Functional anatomy of the vertebrates: an evolutionary perspective, $2^{\text {nd }}$ ed. Saunders College Publishing, Fort Worth, 778 pp.

Ward PS (2001) Taxonomy, phylogeny and biogeography of the ant genus Tetraponera (Hymenoptera: Formicidae) in the Oriental and Australian regions. Invertebrate Taxonomy 15: 589-665. doi: 10.1071/IT01001

Ward PS (2011) Integrating molecular phylogenetic results into ant taxonomy (Hymenoptera: Formicidae). Myrmecological News 15: 21-29.

Watkins II JF (1982) The army ants of Mexico (Hymenoptera: Formicidae: Ecitoninae). Journal of the Kansas Entomological Society 55: 197-247.

Yoder MJ, Mikó I, Seltmann KC, Bertone MA, Deans AR (2010) A gross anatomy ontology for Hymenoptera. PLoS ONE 5: e15991. doi: 10.1371/journal.pone.0015991

Yoshimura M, Fisher BL (2009) A revision of male ants of the Malagasy region (Hymenoptera: Formicidae): Key to genera of the subfamily Proceratiinae. Zootaxa 2216: 1-21.

Yoshimura M, Fisher BL (2011) A revision of male ants of the Malagasy region (Hymenoptera: Formicidae): key to genera of the subfamily Dolichoderinae. Zootaxa 2794: 1-34.

Yoshimura M, Fisher BL (2012) A revision of male ants of the Malagasy Amblyoponinae (Hymenoptera: Formicidae) with resurrections of the genera Stigmatomma and Xymmer. PLoS ONE 7: e33325. doi: 10.1371/journal.pone.0033325

Yoshimura M, Onoyama K (2002) Male-based keys to the subfamilies and genera of Japanese ants (Hymenoptera: Formicidae). Entomological Science 5: 421-443. 